\title{
Percepção da comunidade sobre a poluição por odores de um aterro sanitário na Amazônia Oriental Brasileira
}

A poluição por odores do aterro é um componente dos poluentes que afetam o meio ambiente humano. Questões e reclamações de odores do aterro foram feitas por meio da mídia, reclamações oficiais e protestos de pessoas que moram perto da Central de Processamento e Tratamento de Resíduos (CPTR) Marituba ou comumente chamado aterro sanitário de Marituba. Este estudo tenta obter o feedback das pessoas que vivem perto do aterro sanitário; para isso fo conduzido um estudo por meio de um questionário aplicado aos moradores do entorno do aterro em um raio de $4 \mathrm{~km}$ do aterro. 0 estudo envolve uma pesquisa de percepção para determinar a influência do aterro sanitário no nível social, de saúde, bem-estar, influência do governo na problemática, percepção da qualidade do ar e desconforto. Os resultados dos questionários mostram que os riscos que a população percebe de viver próximo ao aterro de Marituba estão relacionados à sua saúde física e aos efeitos no ambiente físico e social. Os moradores estão insatisfeitos com a qualidade do ar devido a maus odores que causa a CPTR Marituba na área. No contexto da discussão sobre a autopercepção do impacto da CPTR Marituba, isso mostra que os odores e proximidade com o aterro, produz uma emoção negativa e de descontento na população. $O$ estudo encontrou consenso de que o cheiro intenso do aterro de Marituba causa desconforto aos moradores assim como também é uma possível causa de doenças respiratórias. Além disso, a população atribui a presença de moscas como uma maior possibilidade de contrair uma doença gastrointestinal assim também como doenças transmitidas por vectores como Zika, dengue e Chikungunya. Por outro lado, os resultados das entrevistas mostram que há uma variação temporária na qualidade do ar, sendo o cheiro pior no período noturno, depois de ter acontecido chuvas e na estação de inverno. Os resultados desta pesquisa devem ser levados em conta na definição de políticas públicas para a localização de novos aterros sanitários e na implementação de ações para mitigar o impacto negativo dos aterros existentes.

Palavras-chave: Percepção da comunidade; Aterro sanitário; Intensidade do odor; Poluição por odor; Amazônia.

\section{Community perception of odor pullution from a landfill in Brasilian Eastern Amazon}

Landfill odor pollution is a component of the pollutants that affect the human environment. Landfill odor issues and complaints were made through the media, official complaints and protests from people who live near the Marituba Waste Processing and Treatment Center (WPTC) or commonly called Marituba landfill. This study tries to get feedback from people living near the landfill; For this, a study was conducted through a questionnaire applied to the residents around the landfill within a $4 \mathrm{~km}$ radius of the landfill. The study involves a perception survey to determine the landfill's influence on social, health, well-being, government influence on the problem, perception of air quality and discomfort. The results of the questionnaires show that the risks that the population perceives to live near the Marituba landfill are related to their physical health and the effects on the physical and social environment. Residents are dissatisfied with the air quality due to bad odors caused by Marituba WPTC in the area. In the context of the discussion on the self-perception of the impact of Marituba WPTC, this shows that odors and proximity to the landfill, produces a negative and discontented emotion in the population. The study found a consensus that the intense smell of the Marituba landfill causes discomfort to residents as well as being a possible cause of respiratory diseases. In addition, the population attributes the presence of flies as a greater possibility of contracting a gastrointestinal disease as well as diseases transmitted by vectors such as Zika, dengue and Chikungunya. On the other hand, the results of the interviews show that there is a temporary variation in air quality, with the smell being worse at night, after rains and the winter season. The results of this research must be considered in the definition of public policies for the location of new landfills and in the implementation of actions to mitigate the negative impact of existing landfills.

Keywords: Community perception; Landfill; Odor intensity; Odor pollution; Amazon.

Topic: Meteorologia, Climatologia e Mudanças Climáticas

Reviewed anonymously in the process of blind peer.

José Guillermo Machuca Espíritu

Universidade Federal do Pará, Brasil

http://lattes.cnpq.br/1729184732390044

ing.guillermo.es@gmail.com

Breno Cesar De Oliveira Imbiriba

Universidade Federal do Pará, Brasil

http://lattes.cnpq.br/7979656297541988

breno.imbiriba@gmail.com

Jade Rebeka De Souza Ramos

Universidade Federal de Santa Maria, Brasil

http://lattes.cnpq.br/6465951626295491

jade.rebekaramos@gmail.com

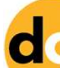

DOI: 10.6008/CBPC2179-6858.2021.005.0018
Received: 10/04/2021

Approved: 09/05/2021

Luciano Louzada do Couto

Universidade Federal do Pará, Brasil

http://lattes.cnpq.br/5626814417988694

luciano.ufpa@gmail.com

Thomas Adalbert Mitschein

Universidade Federal do Pará, Brasil

http://lattes.cnpq.br/7431424927108512

tom@ufpa.br

\section{Referencing this:}

ESPÍRITU, J. G. M.; IMBIRIBA, B. C. O.; RAMOS, J. R. S.; COUTO, L. L.; MITSCHEIN, T. A.. Percepção da comunidade sobre a poluição por odores de um aterro sanitário na Amazônia Oriental Brasileira. Revista Ibero Americana de Ciências Ambientais, v.12, n.5, p.199-209, 2021. DOI: http://doi.org/10.6008/CBPC2179-6858.2021.005.0018 


\section{INTRODUÇÃO}

A gestão integral dos Resíduos Sólidos Urbanos (RSU) continua sendo um tema pendente para a América Latina e o Caribe (ALC). Segundo o Banco Mundial (BM), a geração dos RSU nesta área do mundo deverá aumentar de 130 milhões de toneladas produzidas em 2012 para 220 milhões de toneladas em 2025 (HOORNWEG, 2012; BHADA-TATA, 2012).

Na América Latina e o Caribe (ALC), a agenda da gestão integral dos RSU possui aspectos que ainda precisam de atenção prioritária, devido ao predominante subfinanciamento para a disposição final do RSU; Segundo Hoornweg et al. (2009) o gasto médio dos municípios para a gestão do RSU é de 2-8\% do orçamento dos municípios. Isso se traduz em vários problemas: a falta de pessoal treinado na gestão de resíduos sólidos (especialmente fora das megacidades da $A L C$ ); a cobertura da coleta de RSU, que embora seja alta (93\%), apresenta diferenças extremas entre países, como os casos do Haiti e da Guatemala; a taxa de disposição adequada de RSU, ainda é baixa, já que apenas 54\% dos RSU estão depositadas em aterros sanitários (ONU, 2012). No Brasil, a média nacional de disposição adequada dos RSU é de cerca de $42 \%$ (ABRELPE, 2016), no México, de 74,5\% (SEMARNAT, 2016), e o Chile, país que reporta a maior disposição na ALC, é de 78\% (SUBDERE, 2018).

Além do exposto, o aumento da população, das taxas de geração dos RSU e a baixa educação ambiental da população que despeja seus resíduos em locais públicos, vias públicas, ao ar livre, córregos, rios e lagoas se traduz na deterioração das condições sanitárias urbanas com consequentes problemas de saúde pública e contaminação ambiental (OPAS-AIDIIS-BID, 2010). Outras questões relevantes como a interferência do setor privado na gestão dos resíduos sólidos urbanos (recolha e disposição), a inclusão dos catadores (separadores informais de resíduos sólidos) e a influência da disposição dos RSU no contexto de mudança climática, ressaltam a importância da geração dos RSU na ALC (HERNÁNDEZ-BERRIEL et al, 2016).

A determinação da influência da poluição do ar na saúde humana é extremamente complexa e difícil, a convivência dos seres vivos, em especial a do Homem, com a poluição do ar tem trazido consequências sérias para a saúde. Os efeitos dessa exposição têm sido marcantes e plurais quanto à sua abrangência na população em geral (ALMEIDA, 2003; RODRIGUES, 2003). A poluição atmosférica provoca doenças respiratórias, tais como asma, bronquite e enfisema pulmonar e desconforto físico, donde se destacam a irritação dos olhos, nariz e garganta, dor de cabeça, sensação de cansaço e tosse; também agrava doenças cardiorrespiratórias e contribui para o desenvolvimento de cancro do pulmão. Estes problemas têm alto custo social, como gastos nos tratamentos de saúde, perda de horas de trabalho e redução da produtividade (MIRANDA, 2007).

Outro aspecto da contaminação atmosférica refere-se a odores que são frequentemente uma questão fundamental para os aterros sanitários, especialmente aqueles que recebem resíduos biodegradáveis. Odores normalmente estão associados a atividades como o manuseio de resíduos odoríferos e a cobertura de resíduos biodegradáveis ou com a presença de componentes residuais em gás de aterro ou lixiviados (HPA, 2011). 
As emissões odoríferas são frequentemente acompanhadas por relatos de problemas de saúde das comunidades (STEINHEIDER, 1999). Indivíduos afetados podem relatar uma ampla gama de sintomas de saúde não específicos, atribuindo-os à exposição a odores, incluindo náuseas, dores de cabeça, sonolência, fatiga e problemas respiratórios. Os sintomas de saúde relatados em associação com emissões odoríferas podem surgir em concentrações detectáveis olfatórias bem abaixo dos níveis associados a efeitos tóxicos ou limiares para a irritação da membrana mucosa (HPA, 2011).

As respostas individuais aos odores são altamente variáveis e são influenciadas por muitos fatores, incluindo sensibilidade, idade e exposição prévia ao odor. Fatores psicológicos e sociais, além do nível de preocupação de um indivíduo com o dano potencial à sua saúde, também terão um papel importante na resposta de um indivíduo. Existem estudos publicados que mostram uma forte correlação entre o incômodo percebido pelo odor e os sintomas subjetivos (DALTON et al., 1997; DALTON, 2003). A presença de odores detectáveis pode causar incômodo entre a população local, possivelmente levando a estresse e ansiedade. Algumas pessoas podem sentir sintomas como náusea ou tontura como uma reação aos odores, mesmo quando as concentrações desses produtos químicos são insuficientes para serem diretamente prejudiciais à saúde (HPA, 2011).

Na Região Metropolitana de Belém, Pará, Brasil; o destino do Resíduo Sólido Urbano (RSU) coletado é a Central de Processamento e Tratamento de Resíduos (CPTR) Marituba ou mais conhecido como aterro de Marituba, de criação no ano de 2015, que causou descontentamento na população do entorno. De acordo com Vasconcelos Junior et al. (2017) o empreendimento não foi adequado de forma técnica às normas estabelecidas na Política Nacional de Resíduos Sólidos (PNRS) no que tange ao distanciamento de reservas naturais, ao solo, aos lençóis freáticos etc., para que o aterro opere de forma apropriada.

A Prefeitura do Município de Belém (PMB) deposita cerca de 30.000 toneladas de resíduos sólidos por mês na CPTR Marituba e o total de recebimento de resíduos sólidos no aterro é de cerca de 40.000 toneladas de resíduo\mês, ou seja, Belém equivale a $75 \%$ desse total por isso a necessidade de uma área tão grande destinada ao aterro. Além da PMB outras duas prefeituras da RMB também depositam seus resíduos no aterro (Marituba e Ananindeua) (VASCONCELOS JUNIOR et al., 2017).

Neste aterro sanitário há coleta seletiva, e é realizada pela Associação de Catadores e Recicladores de Materiais Recicláveis de Marituba (ACAREMA). A ACAREMA tem 35 pessoas associadas, sendo que parte delas trabalha no aterro e o restante na sede da associação na cidade de Marituba. Os catadores separam os resíduos enviados ao aterro e o resultado deste trabalho é responsável pela sobrevivência deles (SANTOS et al., 2018).

O anterior aterro, o aterro do Aurá, conhecido como Lixão do Aurá, desativado em julho de 2015, causou os mesmos impactos ambientais dentre os quais, se destacou o forte odor, causado pela decomposição de matérias de origens distintas (alimentos, animais etc.), o que ocasionou o aparecimento de moscas, ratos, entre outros agentes transmissores de doenças. O lixão de Aurá operou por cerca de 20 anos atendendo os municípios de Belém, Ananindeua, Marituba, Benevides e Santa Barbara e recebendo por dia quase duas mil toneladas de resíduos. Neste lixão os RSU não recebiam nenhum tipo de 
tratamento. (SANTOS et al., 2018). Lobato et al. (2012) relatam na sua pesquisa que o solo e rios próximos foram contaminados pelo chorume produzido pelo lixão.

O município de Marituba se destacou nas mídias de comunicação local, devido aos diversos protestos realizados pela população local que exigem providências ao governo municipal, no que concernem as inadequações do empreendimento que gerencia o aterro sanitário, instalado no ano de 2016, e que causou problemas de saúde principalmente doenças respiratórias devido ao forte odor (SANTOS et al., 2018).

O projeto inicial da CPTR Marituba sofreu alterações, uma vez que durante a sua execução não apresentou resultados esperados devido às condições climáticas da região. Após de despejar os RSU pelos caminhões, uma caçamba passa para aterrar o local e assim evitar que a chuva infiltre e gere chorume, além de diminuir o odor. Devido ao clima chuvoso da região, o trabalho tinha que ser paralisado porque o risco de acidente é muito alto. As obras de terraplanagem eram feitas só no verão (quando a incidência de chuvas é menor) porque o material precisava estar seco. (A solução encontrada para que o lixo aterrado não desabasse, foi cobri-lo com lonas, e não com grama como se tinha pensado anteriormente, porque assim impedem a impermeabilização da chuva). A Revita passou um ano sem armazenar o chorume e só fazia tratamento de uma parte do mesmo, pois segundo denúncias da população ao Ministério Público do Estado (MPE), uma parte do chorume gerado no aterro tem sido descartada diretamente na Natureza, provocando danos ambientais (SANTOS et al., 2018).

Em março de 2017, a Secretaria de Meio Ambiente e Sustentabilidade - SEMAS apresentou uma notificação onde foram estabelecidos prazos para a regularização do aterro sanitário e descritas as medidas técnicas emergenciais para a correção das falhas detectadas pela equipe que inspecionou o empreendimento (VASCONCELOS JUNIOR et al., 2017).

A população que mora no entorno do aterro, nas proximidades do rio Uriboca tem sofrido diretamente com o forte odor, doenças da pele, e contaminação do ar e da água pelo mau tratamento dos RSU, empresários e pequenos comerciantes reclamam que a contaminação da água e o mau cheiro tem prejudicado o comércio local (VASCONCELOS JUNIOR et al., 2017).

De acordo com Santos et al. (2018) diversos protestos foram realizados por moradores do município, movimentos sociais, e outros segmentos da sociedade civil, a fim de sinalizar o poder público quanto aos problemas enfrentados no município, cuja reinvindicação dá nome ao movimento chamado "fora lixão!", a qual exige a retirada definitiva do aterro.

Este trabalho tem como objetivo avaliar, de maneira sistemática utilizando questionários, a percepção de qualidade do ar dos moradores do entorno de um aterro sanitário em uma área urbana em uma grande metrópole tropical úmida, os impactos causados na vida dessas pessoas e a como eles julgam a reação popular e a gestão pública dessa situação.

\section{METODOLOGIA}

O local de estudo é a Central de Processamento e Tratamento de Resíduos (CPTR) Marituba ou 
também conhecido como Aterro Sanitário de Marituba (ASM) , localizado na rodovia BR-155, 6959, com coordenadas geográficas de latitude $1^{\circ} 23^{\prime} 53.47^{\prime \prime}$ S e longitude $48^{\circ} 20^{\prime} 25^{\prime \prime} \mathrm{W}$; a aproximadamente $4 \mathrm{~km}$ do centro de Marituba, na Região Metropolitana de Belém (RMB), e ocupa uma área de 111 ha, sendo 78 ha destinados ás Unidades de Processamento/Tratamento e Infraestrutura de Apoio e 32 ha de Área de Preservação Ambiental (REVITA, 2011), a área aterrada atual possui uma altura de 40 metros e se planeja fazer 3 células de expansão (SANTOS et al., 2018).Tem um tempo mínimo de operação de 15 anos e 5 meses de acordo com o Relatório de Impacto Ambiental (RIMA) (REVITA, 2011) (Figura. 1).

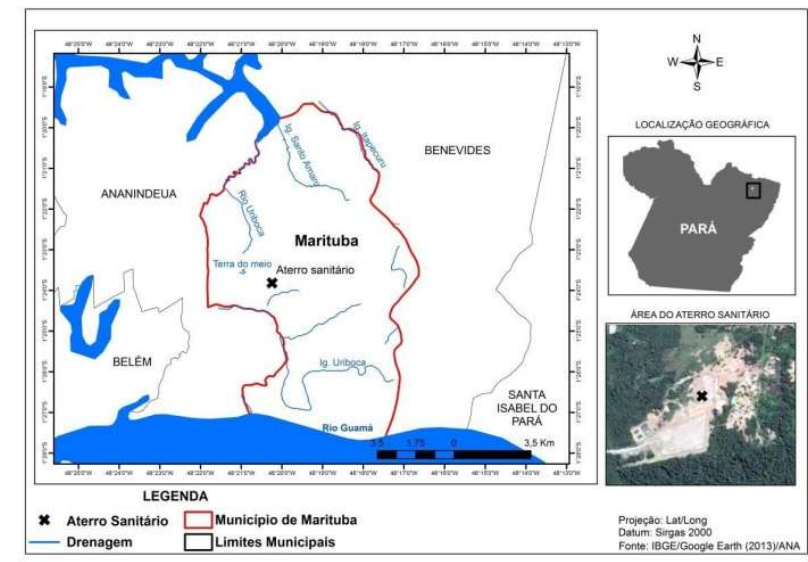

Figura 1: Localização da CPTR Marituba. Fonte: PONTES et al. (2017).

O uso e cobertura da terra no entorno do Aterro Sanitário é constituída de: Área urbana; Floresta; Vegetação Secundária, hidrografia, entre outras) e como é perceptível o Aterro foi construído dentro de uma área urbana do município de Marituba (Figura 2) (PONTES et al., 2017).
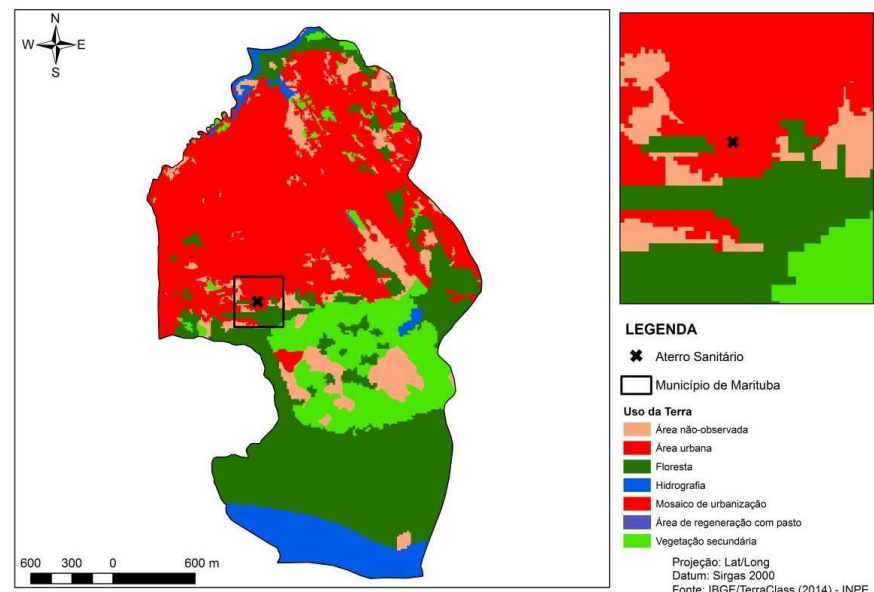

Figura 2: Uso e cobertura da terra no entorno da CPTR Marituba. Fonte: PONTES et al. (2017).

As entrevistas foram feitas com um questionário de 41 perguntas, direitas, de opção múltipla, em algumas perguntas o entrevistado poderia responder uma ou várias opções, e um apartado com os comentários do entrevistado que não entravam nas respostas preestabelecidas e outro apartado com observações do entrevistador. O tempo aproximado de aplicação de cada questionário foi de aproximadamente 10 minutos. Este é dividido em 4 partes: Demografia - para a classificação das pessoas em sexo, idade, estado civil, escolaridade etc; Qualidade do ar - avaliação direta da percepção do impacto com relação à intensidade, hora de maior influência, sazonalidade, variação ao longo do tempo, impacto no 
dia a dia, e vantagens/desvantagens da presença do aterro; Influência do Governo - avaliação da presença do governo na negociação dos possíveis problemas; Impacto na saúde - avaliação da percepção do impacto na saúde devido ao aterro sanitário.

A região dentro de um raio de $4 \mathrm{~km}$ ao redor do Aterro Sanitário tem população de 76.628 habitantes (IBGE, 2010). Com este total da população estimou-se que, para ter um erro máximo de 6,5\%, com grau de confiança de 90\%, eram necessários 161 questionários. Notou-se também o fato de que certas áreas de entrevista eram de alguma periculosidade, dificultando assim o acesso tranquilo a certas ruas pelo que os questionários foram concentrados em avenidas e ruas principais.

Os entrevistados (receptores sensíveis) do estudo envolveu exclusivamente os residentes da área de estudo, de ambos os sexos, de diferentes idades, que tivessem pelo menos 1 ano de moradia na região. Foram entrevistados nas proximidades de suas casas durante a pesquisa, os entrevistados foram de diferentes bairros dos municípios de Ananindeua e Marituba.

\section{RESULTADOS E DISCUSSÃO}

Os 161 questionários foram aplicados em quatro dias de visitas de campo. Todos os questionários foram aplicados no período da manhã, em dois sábados e em dois dias de semana. Os entrevistados são homens e mulheres em similar proporção ( $52 \%$ e $48 \%$ respetivamente), e a faixa etária mais alta é entre 21 e 30 anos (28\%) A grande maioria dos entrevistados (93\%) já habitava a região ao redor do aterro a mais de 3 anos, ou seja, vivenciaram toda a trajetória desde a implementação do aterro, dos problemas e soluções na questão do impacto do na comunidade. 0 73\% dos entrevistados são de cor de pele parda. A grande maioria dos entrevistados (41\%) completaram até o ensino médio (Tabela 1 ).

Tabela 1: Resumo da demografia dos entrevistados

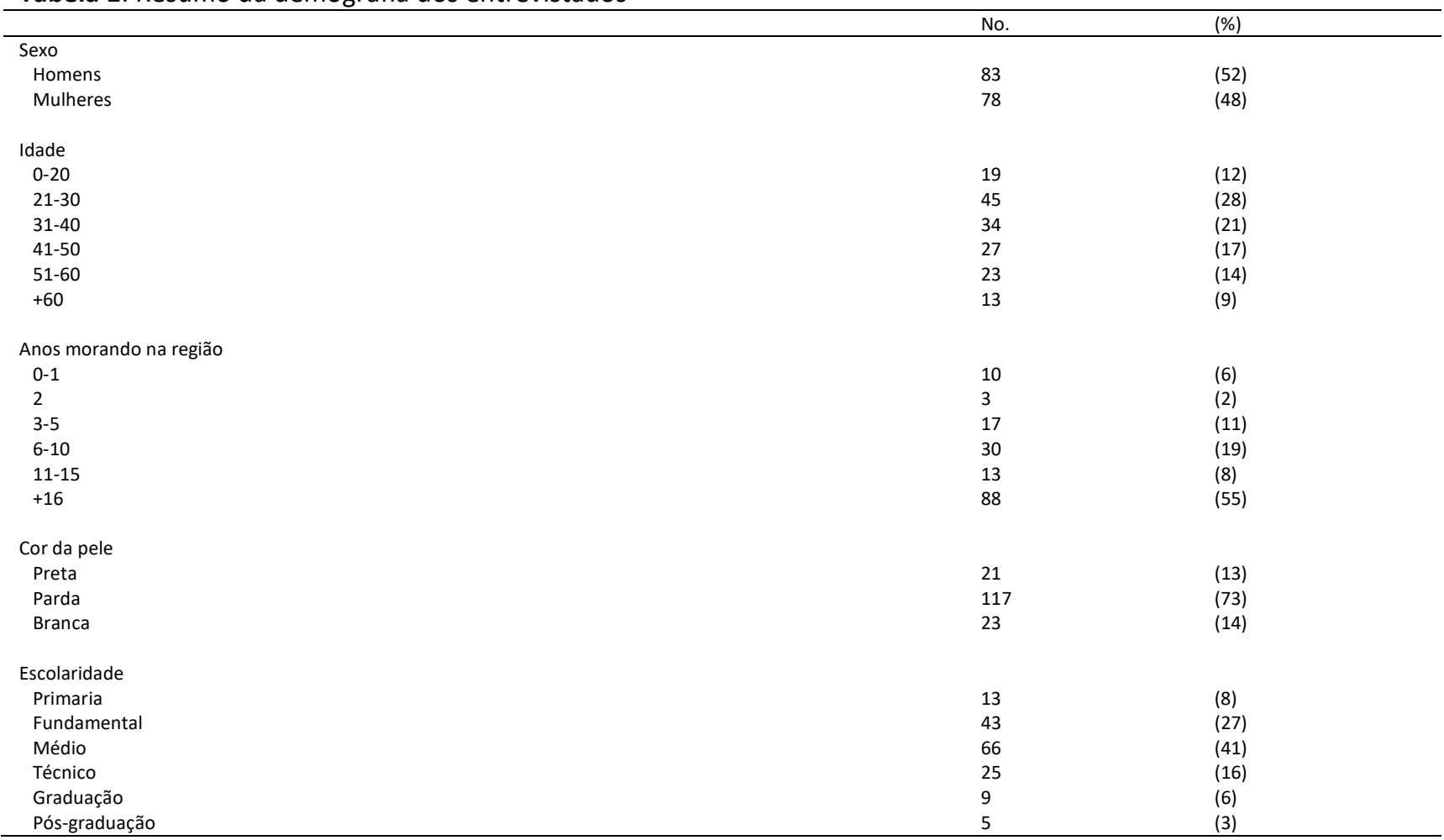


Inicialmente pode se observar a notoriedade com que a população atribui a queda de qualidade do ar na região ao aterro (99\%), causado pelo mau cheiro (83\%). Na graduação do problema, ele incomoda muito (90\%). Um dos resultados mais importantes nesse estudo é a relação entre a meteorologia e a percepção da qualidade do ar. A pior qualidade do ar ocorre durante a madrugada (36\%), seguido por noite e manhã, (28\% e $19 \%$ respectivamente). Também se atribui que os piores momentos ocorrem imediatamente depois das chuvas (77\%) e durante o período de Inverno (85\%).

Quanto à questão do odor, 73\% da população diz que o problema do mau cheiro afetou algo no seu dia a dia. O maior impacto ocorre durante as refeições (39\%) moradores declaram que tiveram que tomar medidas como comer dentro da casa (quem comia no quintal ou no corredor) e o sono (35\%), porém $45 \%$ deles tenta tomar alguma medida para remediar o problema. Repetidos relatos individuais discorrem sobre o cheiro enjoativo na hora da refeição e de dormir, e que tentativas como fechar as janelas durante a noite, forrar a casa, usar ar-condicionado, comer dentro da casa (quem comia no quintal ou no corredor) inclusive usar aromatizantes ambientais para tentar amenizar o problema do mau cheiro.

A população é quase unanime (99\%) com relação ao fato de que não há nem uma vantagem em morar nas proximidades da CPTR Marituba. Moradores do bairro Albatroz de Marituba que fica a menos de $1 \mathrm{~km}$ da CPTR Marituba declaram que muitas pessoas venderam suas casas porque o cheiro era insuportável. Eles também declaram que a única ação ou orientação do governo que eles receberam foi uma cesta básica e água potável porque eles reclamaram que a água dos seus poços foi contaminada. Nesse bairro são poucos os moradores, mas eles protestaram bastante devido a que eles recebiam diretamente os maus odores devido à cercania do bairro com o aterro.

Finalmente, destaca-se que os arredores da CPTR apresentam problemas ambientais adicionais, relacionados, à presença de um canal de esgoto, à existência de pequenos lixões e a água estancada, o que os moradores consideram afeta também o ambiente físico e a saúde (Tabela 2).

Tabela 2: Resumo da percepção do impacto do aterro na qualidade do ar

\begin{tabular}{|c|c|c|}
\hline & No. & (\%) \\
\hline \multicolumn{3}{|c|}{$\mathrm{O}$ aterro piorou a qualidade do ar? } \\
\hline Sim & 159 & (99) \\
\hline Não & 2 & (1) \\
\hline \multicolumn{3}{|l|}{ De que forma? } \\
\hline Mal cheiro & 133 & (83) \\
\hline Poeira & 14 & (9) \\
\hline Fumaça & 13 & (8) \\
\hline Outros & 1 & (1) \\
\hline \multicolumn{3}{|c|}{ O problema incomoda? } \\
\hline Não & 0 & (0) \\
\hline Pouco & 6 & (4) \\
\hline Mais ou menos & 10 & (6) \\
\hline Muito & 145 & (90) \\
\hline \multicolumn{3}{|l|}{ Pior horário } \\
\hline Madrugada & 57 & (36) \\
\hline Manha & 30 & (19) \\
\hline Tarde & 29 & (18) \\
\hline Noite & 45 & (28) \\
\hline \multicolumn{3}{|c|}{ É pior em situação de } \\
\hline Sol & 7 & (4) \\
\hline Chuva & 124 & (77) \\
\hline Calor & 2 & (1) \\
\hline
\end{tabular}




\begin{tabular}{|c|c|c|}
\hline Vento & 26 & (16) \\
\hline Outros & 2 & (1) \\
\hline \multicolumn{3}{|c|}{ Piora em alguma época? } \\
\hline $\operatorname{Sim}$ & 118 & (73) \\
\hline Não & 43 & (27) \\
\hline \multicolumn{3}{|l|}{ Qual época? } \\
\hline Verão & 24 & (15) \\
\hline Inverno & 137 & (85) \\
\hline \multicolumn{3}{|c|}{ Afetou o dia a dia? } \\
\hline Sim & 118 & (73) \\
\hline Não & 43 & (27) \\
\hline \multicolumn{3}{|c|}{ O que afetou? } \\
\hline Sono & 57 & (35) \\
\hline Refeição & 63 & (39) \\
\hline Lazer & 17 & (11) \\
\hline Estudo & 9 & (6) \\
\hline Trabalho & 13 & (8) \\
\hline Outros & 2 & (1) \\
\hline
\end{tabular}

Para a maioria dos entrevistados (91\%) não houve nenhuma ação do governo para lidar com o problema do mau cheiro. Isso sugere uma falta de diálogo entre o governo e a população, tanto para orientar quanto para agir. Dos poucos que sabiam de alguma ação do governo (9\%), a absoluta maioria (93\%) não viu nenhum resultado positivo. Continuando nesta direção, a grande maioria das pessoas (92\%) não viu nenhuma melhora na atuação do governo no último ano (2017).

No entanto, a maioria da população (78\%) lembra-se de ações da comunidade para lidar com o problema da CPTR Marituba, porém a grande maioria (76\%) não acreditou que houve algum efeito positivo duradouro dessas ações populares. Sobre a provável causa do problema, as opiniões dividem-se igualmente entre atribuir o maior problema ao tratamento do resíduo, a localização do aterro e a falta de fiscalização (38\%, 31\% e 30\% respectivamente). A questão dos resíduos sólidos é complexa e não se espera que o cidadão médio tenha opiniões pré-formuladas sobre o assunto, explicando a distribuição uniforme entre as três opções (Tabela 3).

Tabela 3: Resumo da percepção da influência do governo e a sociedade no problema, e a percepção do impacto na saúde

\begin{tabular}{|c|c|c|}
\hline & No. & $(\%)$ \\
\hline \multicolumn{3}{|c|}{ Houve alguma ação do governo? } \\
\hline Sim & 14 & (9) \\
\hline Não & 147 & (91) \\
\hline \multicolumn{3}{|c|}{ Ação do governo surtiu algum efeito? } \\
\hline Sim & 11 & (7) \\
\hline Não & 150 & (93) \\
\hline \multicolumn{3}{|c|}{ Atuação do governo no último ano } \\
\hline Melhor & 13 & (8) \\
\hline Mesmo & 113 & (70) \\
\hline Pior & 35 & (22) \\
\hline \multicolumn{3}{|c|}{ Houve alguma ação da comunidade } \\
\hline Sim & 126 & (78) \\
\hline Não & 35 & $(22)$ \\
\hline \multicolumn{3}{|c|}{ Ação da comunidade surtiu algum efeito? } \\
\hline Sim & 38 & (24) \\
\hline Não & 123 & (76) \\
\hline \multicolumn{3}{|c|}{ Atribui o problema do aterro á } \\
\hline Local & 50 & (31) \\
\hline Tratamento & 61 & (38) \\
\hline
\end{tabular}




\begin{tabular}{|c|c|c|}
\hline Fiscalização & 48 & (30) \\
\hline Outros & 2 & (1) \\
\hline \multicolumn{3}{|c|}{ Causou algum problema de saúde? } \\
\hline Sim & 84 & $(52)$ \\
\hline Não & 77 & (48) \\
\hline \multicolumn{3}{|c|}{ Recebeu atenção médica? } \\
\hline Sim & 72 & (45) \\
\hline Não & 89 & (55) \\
\hline \multicolumn{3}{|c|}{ Receber atenção médica resolveu o problema de saúde? } \\
\hline Sim & 123 & (24) \\
\hline Não & 38 & (76) \\
\hline
\end{tabular}

Os moradores da área adjacente a CPTR Marituba têm a percepção de que os odores provenientes do aterro influenciam em doenças respiratórias, principalmente para crianças e idosos. Os entrevistados consideram que a inalação dos maus odores da CPTR Marituba gera doenças do tipo respiratório como garganta irritada, falta de ar, tosse; sendo estes os principais problemas de saúde que os afligem.

No entanto, os entrevistados relatam que os maus odores não são permanentes, mas que a sua presença está associada às condições meteorológicas como depois da chuva assim também nas horas da noite quando o cheiro é mais intenso. Além disso, comentários diretos feitos pelos entrevistados indicam que os moradores distinguem claramente os odores provenientes da CPTR Marituba daqueles oriundos de outras fontes, como o canal de esgoto ou lagoas de águas pluviais estagnadas, também localizadas em seus setores residenciais.

Com o exposto, mostra-se que os odores não afetam apenas a saúde, mas o bem-estar, devido ao desconforto que geram, tanto no interior das casas como no exterior. Portanto, os moradores evitam passear nas áreas verdes do bairro por causa do aborrecimento causado pelos maus cheiros. Ao investigar os moradores sobre outros efeitos à saúde causados pelo aterro, eles comentam doenças como vômitos, náuseas, problemas da pele, dores de cabeça assim também comentam doenças transmitidas por vetores em específico por mosquitos como são Zika, Dengue e Chikungunya. Finalmente, os moradores consideram que a presença de muitas moscas, não só gera desconforto, mas também aumenta a possibilidade de transmissão de doenças do tipo gastrointestinal (vômitos, náuseas, diarreia).

Independentemente se os gases do aterro realmente causaram algum problema de saúde (algo que apenas uma investigação detalhada na área da saúde pode avaliar) pode-se constatar que houve incomodo suficiente atribuído ao aterro para que as pessoas fossem ao posto de saúde, e mesmo que tais gases possivelmente não causassem algum problema sério, este aparentemente afeta a qualidade dor ar que é respirado pela população circundante.

\section{CONCLUSÃO}

Os resultados dos questionários mostram que a população percebe uma relação negativa entre viver próximo ao CPTR Marituba e a sua saúde física e mental e a qualidade do ambiente em que vivem. Encontrou-se que a inalação dos maus odores causa desconforto na população e é considerada como uma possível causa de doenças respiratórias. Além disso, a população atribui a presença de moscas como uma maior possibilidade de contrair uma doença gastrointestinal assim também como doenças transmitidas por 
vectores como Zika, dengue e Chikungunya.

Embora a intensidade dos odores e sua capacidade de causar desconforto correspondam a avaliações subjetivas e, portanto, podem variar de pessoa para pessoa, neste caso, o estudo encontrou consenso de que o cheiro intenso da CPTR Marituba causa desconforto aos moradores. Por outro lado, os resultados das entrevistas mostram que há uma variação temporária na qualidade do ar, sendo o cheiro pior no período noturno, depois de ter acontecido chuvas e na estação de inverno.

Os moradores estão insatisfeitos com a qualidade do ar devido a maus odores que causa a CPTR Marituba na área. No contexto da discussão sobre a autopercepção do impacto da CPTR Marituba, isso mostra que os odores e proximidade com o aterro, produz uma emoção negativa e de descontento na população.

Por último, destaca-se que os supostos achados nesta pesquisa podem ter implicações para a saúde pública, uma vez que evidenciam o impacto negativo no bem-estar devido à proximidade da CPTR Marituba, além dos efeitos na saúde física que eles poderiam ocasionar e que só uma pesquisa na área da saúde poderia confirmar. Os resultados desta pesquisa devem ser levados em conta na definição de políticas públicas para a localização de novos aterros sanitários e na implementação de ações para mitigar o impacto negativo dos aterros existentes.

Embora da relevância da temática abordada nesse trabalho, estudos sobre percepção da comunidade sobre a poluição por odores de aterros na Região Amazônica são escassos ou inexistentes na literatura. Portanto este trabalho ajudaria a acrescentar as pesquisas respeito aos aterros sanitários nas áreas urbanas e a afetação na qualidade de vida dos moradores na região metropolitana de Belém e da Amazônia.

\section{REFERÊNCIAS}

ALMEIDA, J. P.; RODRIGUES, J.. Um modelo gaussiano incorporado em SIG para estudo de impactos ambientais: aplicação a um caso na zona de Coimbra. Instituto de Engenharia de Sistemas e Computadores de Coimbra. Coimbra, 2003.

DALTON, P.. Upper airway irritation, odor perception and health risk due to airborne chemicals. Toxica Lett, v.140, p.239-480, 2003.

DALTON, P.; WYSOCKI, C.; BRODY, M.; LAWLEY, H.. The influence of cognitive bias on the perceived odor, irritation, and health symptoms from chemical exposure. Int Arch Occup Environ Health, v.69, n.6, p.407-417, 1997.

HPA. Health Protection Agency. Impact on Health of Emissions from Landfill Sites. London: Health Protection Agency, 2011.

HOORNWEG, D.; BHADA-TATA, P.. What a waste: a global review of solid waste management. The World Bank, n.15, 2012.

HERNANDEZ-BERRIEL, M. C.; AGUILAR-VIRGEN, Q.; TABOADA-GONZALEZ, P.; LIMA MORRA, R.; ELJAIEK-URZOLA, M.; MARQUEZ-BENAVIDES, L.; BUENROSTRO-DELGADO, O..
Generación y composición de los residuos sólidos urbanos en América latina y el Caribe. Rev. Int. Contam. Ambie, v.32, p.11-22. DOI: http://doi.org/10.20937/RICA.2016.32.05.0.2016

HOORNWEG, D.; GIANNELLI, N.. Managing municipal solid waste in Latin America and the Caribbean. Integrating the private sector, harnessing incentives. Gridlines, v.28, p.1-4, 2009.

LOBATO, C. C. S.; TAVARES, L. C.. Problemas causados pelo Lixão do Aurá. CONGRESSO NORTE NORDESTE DE PESQUISA E INOVAÇÃO. Anais, Palmas, 2012.

MIRANDA, A.. Efeitos da Poluição Atmosférica: exposição e saúde. Universidade de Aveiro, Aveiro, 2007.

ONU. Organización De Naciones Unidas. Estado de las ciudades de américa latina y el caribe 2012: rumbo a una nueva transición urbana, 2012.

OPS. Organización Panamericana De La Salud; AIDIS. Asociación Interamericana De Ingeniería Sanitaria Y Ambiental; BID. Banco Interamericano De Desarrollo. Informe de la Evaluación Regional del Manejo de Residuos Sólidos Urbanos en América y el Caribe 2010, 2010. 
PONTES, A. K. S.; SOARES, I. R. C.; SILVA, P. V. C.; MORAES, E. T. I.; SANTOS, J. T. S.. Análise da paisagem e formas de uso do solo, no aterro sanitário de Marituba/PA, através da ferramenta SIG, 2017.

REVITA. Relatório de impacto ambiental: resumo das informações sobre a central de processamento e tratamento de resíduos classe II, 2011.

SANTOS, S. L.; FONTEL, Q. J.; PEREIRA, S. V. C.. O tratamento de resíduos sólidos na região metropolitana de Belém. In: CONGRESSO SUL-AMERICANO DE RESÍDUOS SÓLIDOS E SUSTENTABILIDADE, 1. Anais. Gramado, 2018

SECRETARIA DE MEDIO AMBIENTE Y RECURSOS NATURALES.
Informe de la situación del Medio Ambiente em México 2016.

STEINHEIDER, B.. Environmental outdoors and somatic complaints. International Journal of Hygiene and Environmental Medicine, v.202, 101-190, 1999.

SUBDERE. Subsecretaría De Desarrollo Regional Y Administrativa. Programa Nacional de Residuos Sólidos. Gobierno de Chile, 2018.

VASCONCELOS JUNIOR, M. R. V.; CORRÊA, R. S. S.. Impactos Socioambientais Causados pelo Aterro Sanitário no Município de Marituba-PA, 2017.

A CBPC - Companhia Brasileira de Produção Científica (CNPJ: 11.221.422/0001-03) detém os direitos materiais desta publicação. Os direitos referem-se à publicação do trabalho em qualquer parte do mundo, incluindo os direitos às renovações, expansões e disseminações da contribuição, bem como outros direitos subsidiários. Todos os trabalhos publicados eletronicamente poderão posteriormente ser publicados em coletâneas impressas sob coordenação da Sustenere Publishing, da Companhia Brasileira de Produção Científica e seus parceiros autorizados. Os (as) autores (as) preservam os direitos autorais, mas não têm permissão para a publicação da contribuição em outro meio, impresso ou digital, em português ou em tradução. 